NBER WORKING PAPER SERIES

\title{
US-EUROPE DIFFERENCES IN TECHNOLOGY-DRIVEN GROWTH: QUANTIFYING THE ROLE OF EDUCATION
}

\author{
Dirk Krueger \\ Krishna Kumar \\ Working Paper 10001 \\ http://www.nber.org/papers/w10001 \\ NATIONAL BUREAU OF ECONOMIC RESEARCH \\ 1050 Massachusetts Avenue \\ Cambridge, MA 02138 \\ September 2003
}

This paper has been prepared for the April 2003 Carnegie-Rochester Conference. We are grateful to B. Ravikumar for his incisive and detailed suggestions, and to Aris Protopapadakis, Selo Imrhoroglu, and the participants at the Carnegie-Rochester Conference for their comments. Charlotte Yeo provided excellent research assistance. Krueger acknowledges support from NSF grant SES-0004376 and Kumar from the USC Marshall School's research fund. The views expressed herein are those of the authors and are not necessarily those of the National Bureau of Economic Research.

C2003 by Dirk Krueger and Krishna Kumar. All rights reserved. Short sections of text, not to exceed two paragraphs, may be quoted without explicit permission provided that full credit, including $(\subset$ notice, is given to the source. 
US-Europe Differences in Technology-Driven Growth: Quantifying the Role of Education Dirk Krueger and Krishna Kumar

NBER Working Paper No. 10001

September 2003

JEL No. O40, O30, I21

\section{$\underline{\text { ABSTRACT }}$}

European economic growth has been weak, compared to the US, since the 80 s. In previous work (Krueger and Kumar, 2003), we argued that the European focus on specialized, vocational education might have been effective during the $60 \mathrm{~s}$ and $70 \mathrm{~s}$, but resulted in a growth gap relative to the US during the subsequent information age, when new technologies emerged more rapidly. In this paper, we extend our framework to assess the quantitative importance of education policy, when compared to labor market rigidity and product market regulation, other policy differences more commonly suggested to be responsible for US-Europe differences. A "decomposition" exercise using a calibrated version of our model assigns a major role to education policy in explaining US-Europe growth differences.

An electronic appendix for this paper is available at: http:www.nber.org/dataappendix/w10001

Dirk Krueger

Department of Economics

University of Pennsylvania

Philadelphia, PA 19104

and NBER

dkrueger@econ.upenn.edu

Krishna B. Kumar

Department of Finance and Business Economics

USC Marshall School of Business

Los Angeles, CA 90089

kbkumar@usc.edu 


\section{Introduction}

European economic growth has been weak, compared to the US, since the 80s. This is true for the growth rate of per capita GDP as well as for labor productivity in the manufacturing sector. During this period, Europe has also lagged in technology adoption, resulting in a "technology gap" with respect to the US. In previous work (Krueger and Kumar, 2003), we developed a model of education and technology adoption to argue that European focus on specialized, vocational education might have worked well during the 60s and 70s, but not during the subsequent information age when new technologies emerged at a more rapid pace. How important is this policy difference, compared with other explanations, qualitatively and quantitatively? To answer these questions, in this paper we extend the above model to incorporate labor and product market regulations.

In the model, households decide between acquiring general education, which allows them to work in high-tech firms that adopt new technologies, and less costly skill-specific education, which is of value only to low-tech firms that use established production methods. Education policy is captured by the relative subsidy to each type of education. High-tech firms draw a workforce-specific productivity for the new technology, and decide on whether to proceed with production and pay a portion of profits toward regulation costs, or fire the workers at a cost, and redraw a new productivity-workforce combination. The fraction of profits paid to the government is intended to capture the costs of bureaucracy and product market regulations, while the firing cost serves as a proxy for labor market distortions. A firm that decides to proceed with production first chooses the extent of technology adoption; the rate at which new technologies becomes available is exogenously specified, and limits the technology improvement chosen by the firm. Along a Balanced Growth Path (BGP), output grows at the chosen rate of technology adoption.

Our main analytical results are as follows. First, a higher firing or regulation cost causes adopting firms to accept inferior productivity draws, lowering wages and the incentive to acquire general education. The expected growth rate decreases. A higher general education subsidy increases attainment and lowers relative wages for adoption workers. This may increase the rate of technology adoption and growth, even though firms become more willing to accept lower productivity matches. Finally, an increase in the exogenous rate of technological change may increase the growth gap between economies that focus on different types of education, with the economy geared towards skill-specific education falling (further) behind.

We then calibrate our model under the assumption that the US adopts new technologies and grows at the maximal rate, irrespective of whether the exogenous rate of technological change is low or high. Therefore, observed US manufacturing labor productivity growth rates equal the rates of exogenous technological change common to the US and Europe. Given our choice of policy parameters for the US and Europe based on independent empirical evidence, our empirical targets for assessing success of the model are European general education 
attainment and its productivity growth rate - roughly the same as that of the US when technological change is low, but lower when technological change is high. ${ }^{1}$ In other words, our choice of the exogenous rate of technological change enables, but by no means guarantees the quantitative success of our model. Once we have established that the model performs well quantitatively, we use it to study counterfactual policies for Europe that would bridge its growth gap with the US. While a decrease in the firing costs and, to a lesser degree, regulation costs help reduce this gap, a change in education policy explains most of it.

It is important to note that existing growth models, such as those discussed in Stokey and Rebelo (1995), will not yield the implication that two economies growing at potential can diverge when the rate of technological change increases. In a standard model of investment in physical and human capital, differences in relative subsidies to education have the potential to generate differences in the US and European growth rates; however, to obtain the above-mentioned divergence result, modeling education acquisition and technology adoption constrained by the potential rate, as we have done, appears to be necessary.

Relating our study to the existing literature, explanations for US-Europe growth differences are proposed in the collection of papers in Lawrence and Schultze (1987). While the European regulatory environment and labor market frictions receive extensive attention here and elsewhere, we focus on another reason suggested in that volume, to which little attention has been paid. In their words, "Workers must have general training to adapt to new tasks, and European education, which has encouraged apprenticeships that provide specific skills, must adapt."

As in our study, the diminished role of skill-specific education during times of rapid technological progress is also a feature of Galor and Tsiddon (1997) and Galor and Moav (2000). Unlike these papers, we jointly model the technology adoption and education acquisition decision to focus on the effect of education policy on growth. Wasmer (2003) argues that European workers invest more in specific human capital and US workers in general human capital because of differences in labor market institutions. This finding does not preclude the educational system as an independent source of US-Europe differences. ${ }^{2}$

Our formalization of labor market rigidities and product market regulations also has ample precedence in the literature. Pries and Rogerson (2001) use higher firing costs in Europe to capture labor market rigidities, which in their work increases the duration of unemployment through tougher hiring standards. Nagypál (2002) argues that high dismissal costs in Europe hinder learning about match quality and reduce average productivity. Our modeling of product market regulations as a cost is motivated by Nicoletti, Scarpetta, and Boylaud (1999), who identify barriers to entrepreneurship as an important component.

\footnotetext{
${ }^{1}$ We focus on Germany and Italy for our calibration, as these countries' education systems are most different from the US. They are therefore ideal candidates for a quantitative investigation of our hypothesis.

${ }^{2}$ This is true in particular because the vocational focus in Europe predates the rigidity in its labor markets, which may drive Wasmer's observations. See Bertocchi and Spagat (1998).
} 
The rest of the paper proceeds as follows. In Section 2, we present a brief discussion of the stylized facts that motivate our study. The economic environment is presented in Section 3 , and the BGP is characterized in Section 4. Section 5 discusses our calibration, and the quantitative results are presented in Section 6. Section 7 concludes.

\section{Stylized Facts}

In this section, we present a brief summary of the stylized facts that motivate us.

1. A growth gap between the US and Europe has emerged since the $80 \mathrm{~s}$ in per capita growth as well as in labor productivity growth in the manufacturing sector. Scarpetta et. al. (2000), for instance, provide data on relative manufacturing output per person to show that the productivity level for Germany, as in several other European countries, was converging toward the US level until 1980, but the gap has widened since then. They also argue that the manufacturing sector has played a more important role than services in terms of aggregate productivity growth. Growth rates of manufacturing output per worker from the European Competitiveness Report 2001 are presented in Table 1. It can be seen that US labor productivity has outpaced that of the European Union in the 90s, and possibly from earlier on. ${ }^{3}$

Table 1

Manufacturing Labor Productivity Growth

\begin{tabular}{|l||l|l|}
\hline Economy & $1986-1990$ & $1991-2000$ \\
\hline \hline US & $2.3 \%$ & $4.3 \%$ \\
\hline EU & $3.0 \%$ & $3.1 \%$ \\
\hline
\end{tabular}

As mentioned in the introduction, the US growth rates will be used as proxies for the exogenous rates of technological change, while European growth rates will be empirical targets. In Section 5, we tie the independent evidence from Cummings and Violante (2002) and Greenwood and Yorukoglu (1997) on the increase in the rate of embodied technological change during the period under consideration to the rates we assume.

\footnotetext{
${ }^{3}$ The manufacturing productivity growth rates for Germany and Italy were equal to or higher than those of the US during the earlier period of 1970-79. BLS data shows that growth of manufacturing output per hour during 1979-2001 was also lower for Germany (2.4\%) and Italy (2.2\%) when compared to the US (3.2\%).

Germany's productivity growth increased from 2.0\% during 1986-1990 to 3.8\% during 1991-2000, but this figure is confounded by the unification and catchup growth of former East Germany. Italy did better than the US during 1986-1990 (3.8\%), but during 1991-2000, its labor productivity growth of $2.2 \%$ was only half of US growth. We use the average EU growth rates as targets to smooth over country differences within Europe.

The productivity growth gap is even more pronounced in technology-driven industries such as office machineries and computers, pharmaceuticals and aircraft; $8.3 \%$ for the US in the $90 \mathrm{~s}$ and $3.5 \%$ for the EU.
} 
2. There is also evidence that, with the exception of Sweden, Finland, and the Netherlands, a technology gap emerged between the US and Europe during the same period, whether measured by the share of Information and Communication Technology (ICT) equipment investment as a share of total investment or by the contribution of ICT capital to output growth. The contribution of ICT capital to output growth has been increasing for all countries since the 80s, but the gap between the US and European countries has also been increasing. Schreyer (2000) reports that during 1990-1996, 0.42 percentage points of percapita output growth in the US can be attributed to ITC capital-deepening, up from 0.28 points in the second half of the 80s. In Germany, these numbers increased from 0.12 to only 0.18. ${ }^{4}$ Bessen (2002) estimates that technology adjustment costs in the US reached a peak of 90 cents for every dollar invested during 1984-88, and about $10 \%$ of the manufacturing sector output. These facts motivate our modeling of costly technological adoption driving US-Europe growth differences.

3. There is a significant difference in educational focus between the US and Europe, with the US focusing on general education and Europe on vocational education. Vocational enrollment rates at the upper secondary level and beyond are much higher in Europe. On the other hand, in the US the net entry rate into universities, where general education is primarily imparted, is more than twice the rates of most European countries. This results in higher university attainment in the US labor force. The general education attainment in the US, calculated to be $74.5 \%$, is used in the calibration in Section 5, while the attainment in Europe (of $30 \%$ ), will be a crucial empirical target.

While the percentage of GDP devoted to primary and secondary education was about the same for the US and Germany in 1997, the percentage devoted to tertiary education was significantly higher in the US. Consequently, the expenditure per student relative to GDP per capita on tertiary education was higher in the US than in Germany, whereas for post-secondary non-tertiary (vocational) education the situation is reversed. As shown in detail in Section 5, OECD data suggests that the ratio of general to vocational education subsidies corresponding to our model is 2.55 for the US, but only around 1 for Germany and Italy. These will be pre-determined parameters in our calibration exercise.

We are interested in exploring the strength of the education policy channel relative to other policies. As explained in Section 5, the policy parameter for the product market friction is chosen to match entry costs of nearly zero for the US and $5.8 \%$ of gross national income for Germany. The policy parameter for the labor market friction is chosen to match firing costs of nearly zero for the US and six weeks of average wage for Europe.

Given our hypothesis that these stylized facts are related, we now present a model with

\footnotetext{
${ }^{4}$ Italy experienced a similar trend. Stiroh (2002) shows that IT-intensive industries experienced significantly larger labor productivity gains than other industries; he also finds a strong correlation between IT capital accumulation and labor productivity growth.
} 
a household education choice and costly technology adoption choice by firms.

\section{The Environment}

The economy is populated by a continuum of households and two continua of identical firms. Firms in one sector, the adopting or high-tech sector, potentially adopt new technologies in every period, and firms in the nonadopting or low-tech sector do not. ${ }^{5}$ There is a single nonstorable consumption good in each time period and households supply labor to the firms. In this section we describe the maximization problems of a typical firm in each sector and of a typical household, and finally define equilibrium and a balanced growth path.

\subsection{Firms and Technology Adoption}

All firms in our economy are owned by infinitely lived entrepreneurs. Profits are immediately consumed since entrepreneurs, like workers, do not have access to an intertemporal storage technology or long-lived assets.

At each point of time there is a single final consumption good in the economy, which serves as the numeraire. The aggregate technology that is freely available for usage in production by all firms in the current period is denoted by $A$. It is the result of past technology adoption decisions (which are described below) and taken as given by all firms in the current period. A firm in the sector that does not adopt new technologies in the current period produces output according to

$$
Y_{n}=A \beta\left(H_{n}\right)^{\theta}
$$

where $Y_{n}$ is output of a typical nonadopting firm and $H_{n}$ are the effective units of labor employed; $\beta>0$ is a parameter that governs the relative productivity of the low-tech and the high-tech sector, and $\theta<\frac{1}{2}$ is an intensity parameter. As will be described below, each worker in the low-tech sector has productivity $h>1$. Therefore, if the typical nonadopting firm hires $n_{n}$ workers from the competitive labor market, the above production function can be written as $Y_{n}=A \beta\left(n_{n} h\right)^{\theta}$. Every nonadopting firm takes the wage $W_{n}$ per efficiency unit in the sector as given and maximizes profits.

Firms in the technology-adopting ("high-tech") sector can choose the level of technology $a^{\prime}$ with which to produce today, subject to the constraint

$$
a^{\prime} \leq A_{f}
$$

where $A_{f}$ is the productivity level of the frontier technology. This frontier technology is assumed to grow at a constant exogenous rate $\lambda$; next period's frontier technology is given

\footnotetext{
${ }^{5}$ We abstract from important industrial organization issues such as firm entry and exit decisions to keep our model analytically and computationally tractable. However, in Section 6.3, we explore the sensitivity of our quantitative analysis to incorporating entry.
} 
by $A_{f}^{\prime}=\lambda A_{f}$. An adopting firm incurs a technology adoption cost $\frac{A}{2}\left(a^{\prime}-A\right)^{2}$ if it decides to use technology $a^{\prime}$ in the current period and the freely available "common practice" is $A$. It is proportional to the complexity of the common practice $A$ and strictly convex in the distance of the technological "leap". 6

The output of a typical firm in the adopting sector $Y_{a}$ is given by

$$
Y_{a}=a^{\prime}\left(H_{a}\right)^{\theta}
$$

where $H_{a}$ are the effective units of labor employed. As will be described below, $E_{h}$ is the stochastic productivity per worker in this firm. Therefore, if the typical adopting firm hires $n_{a}$ workers, the above production function can be written as $Y_{a}=a^{\prime}\left(n_{a} E_{h}\right)^{\theta}$. Adopting firms take wages $W_{a}$ per efficiency unit as given. ${ }^{7}$

\subsection{Labor and Product Market Regulations}

We model product market regulations and labor market rigidities in a highly stylized way. We discuss these model features while describing the sequence of events within a given period for adopting firms.

1. A representative adopting firm hires $n_{a}$ number of workers.

2. The firm draws a worker productivity level $E_{h} \sim F($.$) , with associated continuous$ probability density function $\tilde{f}$. We assume that $E_{h}$ is perfectly correlated across workers and that draws are independent over time. The productivity draw can be viewed as specific to an adopting firm and the workforce it hires; it captures how effectively the firm can produce the final good if it proceeds with the current implementation of the new technology.

3. Given the above productivity draw for its workforce, the firm decides whether to proceed with the implementation of a new technology and produce the final good accordingly, using the current workforce. If the firm does not implement the technology, it pays a firing cost $A * f n_{a} E_{h}$, instantly hires new workers $n_{a}$ and draws again. Here, $f$

\footnotetext{
${ }^{6}$ If $A$ is viewed as the number of machines, the cost of retooling each machine will be constant on a balanced growth path.

${ }^{7}$ Since a firms' technology does not feature constant returns to scale, it is clear that scale matters in our setup. We have exogenously set the measure of firms in each sector to one, which pins down the scale. In Section 6.3, we check whether this assumption matters quantitatively; it does not.

Mitchell (2002) presents evidence that TFP growth is negatively associated with plant size. Since in our model it will be the case that $a^{\prime} \geq A$, firms with higher productivity levels (the high-tech firms) have higher scale of production. Is this counter to the above evidence? It is not obvious whether the entity in our model that chooses the technology should be a firm or a plant. Moreover, given our spillover assumption both types of firms grow at the same rate on the BGP, albeit with a gap in their productivity levels. Despite this defense, it is clear that our model is not set up to handle issues of firm size distribution.
} 
is the resource cost of firing a unit of effective labor; these resources are lost and don't benefit anyone. ${ }^{8}$ If the firm decides to implement the technology after this "sampling" phase, it chooses the extent of adoption, $a^{\prime}$, optimally. ${ }^{9}$ In order to enter the output ("product") market to sell its product, the firm has to pay a fraction $C$ of its profits from production. This can be viewed as the resource cost of administrative burden and regulatory compliance arising from government policy; again these resources are lost. The firm then pays workers wages $W_{a}$. Output net of wages, regulation, firing and adoption costs is consumed by the adopting entrepreneur as profits.

Several elements of our formulation deserve further discussion. First, the interpretation of the third stage is that there are several ways of implementing a new technology, and some work well, given the labor force, and some do not. If a draw is viewed as building a prototype, or conducting a trial run of production, firing workers is akin to shutting the plant down when the trial run fails, and attempting to re-implement the technology in a different way, hoping for a better productivity match between technology and workers. Since the labor productivity $E_{h}$ is workforce-specific, firing workers is necessary in order to sample the aggregate labor market for a different set of workers. ${ }^{10}$

Second, given that $E_{h}$-draws are independent over time, no firm has an incentive to revise its choice $n_{a}$ after an unsuccessful draw. Third, we assume that new draws can occur instantly, which allows us to abstract from discounting within a model period and does not introduce other issues of timing within a period. ${ }^{11}$ Fourth, the cost parameters $f$ and $C$ are intended to capture labor market frictions and product market regulations, respectively. These costs are proportional to the current technology; this assumption yields the empirically plausible implication that equilibrium costs are a constant fraction of GDP in a growing economy.

\footnotetext{
${ }^{8}$ Qualitatively, little hinges on whether the firing costs are paid per effective unit or raw unit of labor; indeed, in the calibration it is convenient to consider this as the cost per worker. Our assumption that these costs are lost resources that do not benefit anyone is in line with the "real resource costs which include the costs associated with following whatever procedures are necessary in order to dismiss a worker," assumed by Pries and Rogerson (2001).

${ }^{9}$ For instance, a firm decides first on whether it should computerize and what computers work best, before it decides on how much of its operations will be computerized.

${ }^{10}$ We are implicitly assuming that the output produced when the workers are fired is zero; therefore, a failed attempt need not only be viewed as a technology match that did not produce results, but also as a production attempt that resulted in very low output.

${ }^{11}$ However, this will abstract from the cost of waiting for a better productivity draw.
} 


\subsection{The Firms' Problems}

Given the common practice $A$, the static problem of a typical nonadopting firm reads as

$$
\max _{n_{n}} A \beta\left(n_{n} h\right)^{\theta}-W_{n} n_{n} h
$$

with necessary and sufficient first order condition

$$
W_{n}=\theta A \beta\left(n_{n} h\right)^{\theta-1}
$$

Adopting firms have three choices to make in any given period, namely how many workers $n_{a}$ to hire, and then, conditional on a productivity draw, whether to go ahead with production or whether to redraw, and finally, conditional on producing, the extent of adoption, $a^{\prime}$.

Let's first consider the third stage of the problem. Conditional on hiring $n_{a}$ workers and a productivity draw, $E_{h}$, the firm solves

$$
\Pi\left(E_{h}, n_{a}\right)=\max _{a^{\prime} \leq A_{f}} a^{\prime}\left(n_{a} E_{h}\right)^{\theta}-W_{a} n_{a} E_{h}-\frac{A}{2}\left(\frac{a^{\prime}}{A}-1\right)^{2} .
$$

In our framework, the workers are relatively passive and the firm does all the experimenting. There is no bargaining and division of surplus as every worker, by assumption, is paid her marginal product. While the extensive literature on individual worker-firm matching has produced several useful insights, modeling such micro-mechanisms would lead us too far astray from the main purpose of our paper of analyzing labor market friction as a concomitant cause for US-Europe growth differentials. Therefore, it seems least ad-hoc to assume that the firm pays workers their marginal product as wages. We can envision competitive employment agencies that hire the labor force with general education and places it with adoption firms, with the common understanding that workers would be placed in a different firm in case they are not paid competitively. We, therefore, have

$$
W_{a}\left(E_{h}, n_{a}\right)=\theta a^{\prime}\left(n_{a} E_{h}\right)^{\theta-1}
$$

When choosing the level of technology, $a^{\prime}$, the firm takes these wages as given and beyond its control.

The third term in (2) captures the convex cost of upgrading technology, relative to the current best practice. In Section (3.6), we elaborate on the assumption that the increase in technology relative to the aggregate state, $A$, matters for the adoption cost, and also discuss how technology adoption decisions of firms impact next period's common practice.

In the second stage, the firm decides whether to go ahead with production, conditional on a productivity draw $E_{h}$. Let $V\left(E_{h}, n_{a}\right)$ denote the period value of a firm with productivity draw $E_{h}$ and number of workers, $n_{a}$. The function $V$ solves the functional equation

$$
V\left(E_{h}, n_{a}\right)=\max _{\text {adopt, not adopt }}\left\{(1-C) \Pi\left(E_{h}, n_{a}\right),-f n_{a} E_{h} * A+\int_{1}^{h} V\left(E_{h}^{\prime}, n_{a}\right) d F\left(E_{h}^{\prime}\right)\right\},
$$


where the choice is between adopting and producing, or dismissing the workforce and hoping for a more suitable workforce-productivity combination. ${ }^{12}$ We use "proceed" and "adopt" interchangeably, as we do "not adopt" and "fire" or "dismiss". Let $a^{\prime}\left(E_{h}, n_{a}\right)$ denote the optimal technology choice of a firm with productivity draw $E_{h}$ and workers $n_{a}$, and by $\bar{E}_{h}\left(n_{a}\right) \in[1, h]$ the threshold productivity draw above which a firm produces rather than redraws. A unique such threshold exists since the first part of the Bellman equation is strictly increasing in $E_{h}$ (as profits are) and the second part is strictly decreasing in $E_{h}$.

Finally, in the first stage of the firms' problem each firm chooses

$$
n_{a} \in \arg \max _{n} \int V\left(E_{h}, n\right) d F\left(E_{h}\right) .
$$

\subsection{Households and Education Decisions}

There is a measure one of households that live for two periods. Households in our economy make only one economic decision, namely which type of education to obtain in the first period of their lives. A household can opt to obtain vocational or general education. There is a utility cost, $e(a)$, of obtaining general education, which depends on an agent's innate ability $a \in[0,1]$ for higher education. We assume that $a$ is uniformly distributed across the population; therefore, the cumulative distribution function is $F(a)=a$. We also assume that $e(a)$ is strictly decreasing in $a .^{13}$

An agent who acquires vocational education earns a wage $W_{n} h$ in the second period of life. This agent can work in nonadopting firms with the technologies that were adopted last period, and have become established practice this period. This agent's task-specific productivity is at its highest possible value, $h$, because the agent has received training for that specific technology.

The benefit that an agent obtains from general education is qualification to work in the adopting sector with newer technologies. While the technology per se is more productive, the agent's task-specific productivity, $E_{h}$, is stochastic and lies anywhere in $[1, h]{ }^{14}$ This

\footnotetext{
${ }^{12}$ Treating $f, n_{a}>0$ as parametric, one can show that this Bellman equation (normalized by $A$ ) satisfies Blackwell's sufficient conditions, and is indeed a contraction with modulus $F\left(E_{h}^{*}\left(n_{a}\right)\right)<1$, where $E_{h}^{*}\left(n_{a}\right)$ solves $f n_{a} \int_{1}^{E_{h}^{*}} E_{h} d F\left(E_{h}\right)=(1-C) \int_{E_{h}^{*}}^{h} \pi\left(E_{h}, n_{a}\right) d F\left(E_{h}\right)$. In other words, even though there is no discounting, the existence of positive firing costs yields a well-behaved value function. As will be apparent below, $n_{a}=0$ cannot be an equilibrium.

${ }^{13}$ The use of the disutility function $e(a)$ is a reduced form way of modeling probabilistic success in general education that depends on ability.

${ }^{14}$ If we assume that there are only two skill levels, 1 and $h$, and that $T$ is the probability that a generally educated agent is unsuited for the new technology and ends up with the low productivity, the expected agent productivity can be written as $E_{h}=T \cdot 1+(1-T) \cdot h$. Hence the notation $E_{h}$. It is easier to deal with $E_{h}$ directly, instead of the underlying $T$. In Krueger and Kumar (2003) we study conditions under which it is optimal for vocationally educated agents to work only in the nonadopting sector, and generally educated agents to work only in the adopting sector; in this paper, we directly assume it.
} 
agent earns the random wage $W_{a} E_{h}$. Thus, when making the education decision, households confront the trade-off between a higher cost of obtaining general education, net of any subsidy, and a potentially higher wage in the second period of life. ${ }^{15}$

Given that an agent's working life in the model is one period, it is difficult to examine if the above assumptions on worker productivity lead to the potentially counterfactual implication that workers with general education face a riskier earning process. What can be asserted is that randomness in $E_{h}$ is needed only to accommodate a labor market friction for adopting firms in the form of firing costs during the sampling phase. Indeed, if the above-mentioned employment agency provides perfect insurance to agents with general education and guarantees the certainty equivalent of the expected utility from wages, thereby eliminating all risk, the education decision would be unaffected. ${ }^{16}$

We assume that households do not have access to insurance contracts against bad realizations of individual labor productivity and thus consume their wages in the second period of life. Agents have preferences representable by the utility function

$$
U(a)=I_{g}\left\{E \log \left(W_{a} E_{h}\right)-\log (e(a))+\log \left(S_{g}\right)\right\}+\left(1-I_{g}\right)\left\{\log \left(W_{n} h\right)+\log \left(S_{v}\right)\right\}
$$

where $I_{g}=1$ if the household chooses general education and $I_{g}=0$ if the household chooses vocational education. ${ }^{17}$ The expectation $E$ is taken with respect to the stochastic productivity $E_{h}$. Here $S_{g}$ and $S_{v}$ denote government subsidies for general and vocational education, respectively. ${ }^{18}$ Given that all elements apart from $e(a)$ in the utility function are independent of $a$, it follows that there exists a threshold ability level $a^{*}$ above which households choose to obtain general education and below which they obtain vocational education.

\footnotetext{
${ }^{15}$ A breakup of wage profiles by vocationally versus generally educated workers is hard to find. CERGE-EI (1997, VII.2) reports that the age-wage profile for agents with vocational education in the Czech Republic is very flat, while the profile for those with university education starts around the same wage, but shows substantial growth with age. Similar differences are also reported for Canada by Allen (1998). This lends some credibility to our assumption that vocationally educated agents work in the nonadopting sector and do not experience the steep wage growth one would expect in a (high-tech) sector where technology changes rapidly.

${ }^{16}$ See (18) below. A version of the model in Krueger and Kumar (2003) - where agents are longer-lived, vocational agents have a higher probability of skill obsolescence, and both types of agents are free to choose the sector they work for every period - is more suitable to address this issue. Such a model has the potential of generating a higher earnings volatility of the vocationally educated. The qualitative behavior with respect to educational policies in this more complicated setup is identical to that of the present model.

${ }^{17}$ Discounting across periods serves little purpose in our setup, and we have abstracted from it.

${ }^{18}$ The assumption that the subsidy yields utility directly is rationalized by the assumptions that agents care about consumption in both periods of their lives, private credit markets are absent in this two-period OLG framework, and the subsidy yields proportional consumption benefits during the first period of life.
} 


\subsection{Government Education Policy}

We assume that the government spends a total amount of $A * G$ on education. This formulation is consistent with education expenditures that are a constant fraction of GDP along a balanced growth path. Given the threshold $a^{*}$ defined above, the governments' budget constraint, assumed to hold period by period, is

$$
a^{*} S_{v}+\left(1-a^{*}\right) S_{g}=A * G
$$

Even though we do not explicitly model it, one may imagine the government collecting taxes to finance education, through a proportional labor income tax. Given logarithmic preferences, it is the ratio of wages that matters for the education decision, and a proportional tax would not affect this ratio, and therefore our analysis.

\subsection{Equilibrium}

Let $\eta_{g}$ denote the fraction of young agents who obtained general education during the last period and thus are available for work in the high-tech sector. At any point in time the aggregate state of the economy is described by the vector $z=\left(\eta_{g}, A, A_{f}\right)$. In order to define a recursive equilibrium we have to describe the law of motion for the state vector. Next periods' education allocation, $\eta_{g}^{\prime}$, is determined by the decision of young households in the current period; that is, $\eta_{g}^{\prime}=1-a^{*}$. The frontier technology evolves exogenously according to

$$
A_{f}^{\prime}=\lambda A_{f}
$$

The commonly available technology next period, $A^{\prime}$, is assumed to be the average level of technology adopted by high-tech firms this period; that is ${ }^{19}$

$$
A^{\prime}=\left[1-F\left(\bar{E}_{h}\left(n_{a}\right)\right)\right]^{-1} \int_{E_{h} \geq \bar{E}_{h}\left(n_{a}\right)} a^{\prime}\left(E_{h}, n_{a}\right) d F\left(E_{h}\right) .
$$

Individual adopting firms perceive themselves as small and therefore unable to affect tomorrow's aggregate state $A^{\prime}$ through their technology adoption decision today. It is the aggregate technology $A^{\prime}$ rather than the individual technology $a^{\prime}$ that determines tomorrow's starting technology for an adopting firm; this makes its adoption problem, conditional on $E_{h}$, essentially static. Adoption yields a technological advantage only in the current period, via higher current profits, before the competition catches up.

We can view the newly available technology as filled with "bugs", and the process of adoption as discovering these bugs and working around them in order to realize the potential

\footnotetext{
${ }^{19}$ This average is a cross-sectional average over the continuum of firms. We are implicitly assuming a law of large numbers, which allows us to use the distribution function for productivity draws of a single firm, $F$, as the population distribution.
} 
gains of the technology. In the subsequent period, when these bugs become known and fixed, a more robust technology is available to all. In this paradigm, (8) can be interpreted as the expected number of bugs that are discovered this period and will be fixed by the next period.

We can now define a recursive equilibrium:

Definition 1 A Recursive Equilibrium is a policy function for workers, $I_{g}(a ; z)$, a policy function for nonadopting firms, $n_{n}(z)$, a value function $V\left(E_{h}, n_{a} ; z\right)$ and policy functions for the adopting firms, $n_{a}(z), \bar{E}_{h}\left(n_{a} ; z\right), a^{\prime}\left(E_{h}, n_{a} ; z\right)$, wage functions $W_{n}(z)$ and $W_{a}\left(E_{h}, n_{a} ; z\right)$, an education cut-off function $a^{*}(z)$, government policy functions $S_{g}(z), S_{v}(z)$ and an aggregate law of motion $\Phi$ mapping today's aggregate state into tomorrow's aggregate state such that

1. Given wage functions, policy functions by firms, government policy, and the aggregate law of motion, $I_{g}(a ; z)$ maximizes (5) for all $a \in[0,1]$. The education cut-off $a^{*}(z)$ satisfies

$$
I_{g}(a, z)=1 \text { for all } a \geq a^{*}(z) \text { and } I_{g}(a, z)=0 \text { for all } a \leq a^{*}(z) \text {. }
$$

2. $W_{n}(z)$ and $n_{n}(z)$ satisfy $(1) . W_{a}\left(E_{h}, n_{a}, z\right)$ and $n_{a}(z)$ satisfy $(3)$.

3. The value function $V\left(E_{h}, n_{a} ; z\right)$ solves Bellman equation (4) and $\bar{E}_{h}\left(n_{a} ; z\right)$ is the associated optimal productivity cut-off.

4. Given $W_{a}\left(E_{h}, n_{a}, z\right)$, the technology adoption decision solves (2).

5. The government policy satisfies (6), given $a^{*}(z)$.

6. The labor market clears: $\eta_{g}=n_{a}(z)$ and $1-\eta_{g}=n_{n}(z)$.

7. The aggregate law of motion $\Phi$ is induced by the optimal policy functions $I_{g}(a ; z)$ and $a^{\prime}\left(E_{h}, n_{a} ; z\right)$.

The last part of the definition can be explicitly stated in the following way: $A_{f}^{\prime}$ is given by $(7), A^{\prime}$ is given by (8) and $\eta_{g}^{\prime}=1-a^{*}(z)$, where $a^{*}(z)$ is in turn defined by the optimal education acquisition policy $I_{g}(a ; z)$ via $(9)$.

\subsection{Balanced Growth Path}

In our analysis we will restrict ourselves to balanced growth path equilibria. We first normalize all growing variables by dividing by the level of the current technology, $A$. We let $x\left(E_{h}, n_{a}\right)=\frac{a^{\prime}\left(E_{h}, n_{a}\right)}{A}$ denote the growth rate chosen by a generic adopting firm and by $E(x)=\left[1-F\left(\bar{E}_{h}\left(n_{a}\right)\right)\right]^{-1} \int_{E_{h} \geq \bar{E}_{h}} x\left(E_{h}, n_{a}\right) d F\left(E_{h}\right)$ the average growth rate of technology of adopting firms, which by (8) equals the constant aggregate growth rate of the economy along a balanced growth path. 


\subsubsection{Firms}

Dividing the optimality condition for the nonadopting firms by $A$ yields

$$
w_{n}=\theta \beta\left(n_{n} h\right)^{\theta-1}
$$

where $w_{n}=\frac{W_{n}}{A}$ is the normalized wage in the nonadopting sector.

In the adopting sector, conditional on hiring $n_{a}$ workers and drawing a productivity shock $E_{h}$, the firm solves

$$
\pi\left(n_{a}, E_{h}\right)=\max _{x \leq \lambda} x\left(n_{a} E_{h}\right)^{\theta}-w_{a} n_{a} E_{h}-\frac{1}{2}(x-1)^{2},
$$

where the de-trended wage $w_{a}$, taken as given by the firm, equals the marginal product

$$
w_{a}=\theta x\left(n_{a} E_{h}\right)^{\theta-1} .
$$

The dynamic programming problem of the firm becomes

$$
v\left(E_{h}, n_{a}\right)=\max _{\text {adopt, not adopt }}\left\{(1-C) \pi\left(E_{h}, n_{a}\right),-f n_{a} E_{h}+\int_{1}^{h} v\left(E_{h}^{\prime}, n_{a}\right) d F\left(E_{h}^{\prime}\right)\right\}
$$

where $v\left(E_{h}, n_{a}\right)=\frac{V\left(E_{h}, n_{a}\right)}{A}$ is the normalized value function and $n_{a} \in \arg \max _{n} \int v\left(E_{h}, n\right) d F\left(E_{h}\right)$ is the optimal labor demand of the firm.

\subsubsection{Households}

Household preferences can be rewritten as (ignoring constants irrelevant for maximization)

$$
u(a)=I_{g}\left\{E \log \left(w_{a} E_{h}\right)-\log (e(a))+\log \left(s_{g}\right)\right\}+\left(1-I_{g}\right)\left\{\log \left(w_{n} h\right)+\log \left(s_{v}\right)\right\}
$$

where the subsidy levels $s_{v}=\frac{S_{v}}{A}$ and $s_{g}=\frac{S_{g}}{A}$ of the government have to obey its budget constraint

$$
a^{*} s_{v}+\left(1-a^{*}\right) s_{g}=G
$$

\subsubsection{Equilibrium}

Definition 2 A balanced growth path equilibrium is an optimal education decision for workers, $I_{g}(a)$, labor demand for nonadopting firms, $n_{n}$, a value function $v\left(E_{h}, n_{a}\right)$ and polices for the adopting firms, $n_{a}, \bar{E}_{h}\left(n_{a}\right), x\left(E_{h}, n_{a}\right)$, wages $w_{n}$ and $w_{a}\left(E_{h}, n_{a}\right)$, an education cutoff function $a^{*}$, government policies $s_{g}, s_{v}$ and an aggregate growth rate $E(x)$ and education allocation $\eta_{g}$ such that

1. Given wages, $I_{g}(a)$ maximizes (14) for all $a \in[0,1]$. The education cut-off $a^{*}$ satisfies

$$
I_{g}(a)=1 \text { for all } a \geq a^{*} \text { and } I_{g}(a)=0 \text { for all } a \leq a^{*} .
$$


2. Wages satisfy (10) and (12).

3. The value function $v\left(E_{h}, n_{a}\right)$ solves Bellman equation (13) and $\bar{E}_{h}\left(n_{a}\right)$ is the associated optimal productivity cut-off.

4. $x\left(E_{h}, n_{a}\right)$ solves $(11)$.

5. The government policy satisfies (15), given $a^{*}$.

6. The labor market clears: $\eta_{g}=n_{a}=1-a^{*} ; 1-\eta_{g}=n_{n}$.

7. The aggregate growth rate is given by

$$
E(x)=\left[1-F\left(\bar{E}_{h}\right)\right]^{-1} \int_{E_{h} \geq \bar{E}_{h}\left(n_{a}\right)} x\left(E_{h}, \eta_{g}\right) d F\left(E_{h}\right) .
$$

We will use $s=\frac{s_{g}}{s_{v}}$ as our educational policy variable; given $s$ and $G$, the individual subsidies $\left(s_{g}, s_{v}\right)$ can be derived from the definition of $s$ and equation (15).

\section{Qualitative Characterization of the Balanced Growth Path}

In a separate appendix, we analytically characterize the balanced growth path of this economy in detail and conduct comparative statics with respect to the policy parameters $(f, C, s)$ and the speed of technological innovation $\lambda .^{20}$ In this section, we merely summarize these results to highlight the forces behind the quantitative results and present the BGP conditions used to compute them. The adopting firm's problem is solved for a schedule, $\bar{E}_{h}\left(\eta_{g}\right)$ that relates the optimal productivity threshold $\bar{E}_{h}$, beyond which the firm chooses the adoption option, to a given measure $\eta_{g}$ of high-tech labor. A similar schedule, $\bar{E}_{h}^{H H}\left(\eta_{g}\right)$ is derived from the households' education problem - the productivity threshold $\bar{E}_{h}$, with its implied wage differential that is necessary to induce a given measure $\eta_{g}$ of households to work in the high-tech sector. These two schedules are combined to solve for the BGP education allocation $\eta_{g}^{*}$ and productivity threshold $\bar{E}_{h}^{*}$.

\subsection{The Firm Condition}

The first-order condition of the adopting firm's problem in (11), conditional on an acceptable $E_{h}$ draw, motivates the definition of the threshold $\widehat{E}_{h}$ beyond which $x=\lambda$ is optimal (i.e. the speed of technology adoption is maximal),

$$
\widehat{E}_{h}\left(\eta_{g}\right) \equiv \min \left\{\max \left\{1, \frac{(\lambda-1)^{\frac{1}{\theta}}}{\eta_{g}}\right\}, h\right\} .
$$

\footnotetext{
${ }^{20}$ This appendix is available from the authors upon request. Alternatively, it can be found at www.econ.upenn.edu/ $\sim$ dkrueger/appcr.pdf.
} 
There exist cutoffs $\eta_{g}^{1}$ and $\eta_{g}^{3}$, such that, for $\eta_{g} \in\left[1, \eta_{g}^{1}\right]$ only interior growth occurs, for $\eta_{g} \in\left[\eta_{g}^{1}, \eta_{g}^{3}\right]$ either interior (when the draw $E_{h}<\widehat{E}_{h}$ ) or maximal growth (when $E_{h} \geq \widehat{E}_{h}$ ) is possible, and for $\eta_{g} \in\left[\eta_{g}^{3}, 1\right]$ only maximal growth occurs. ${ }^{21}$

Using the adopting firm's first order conditions we obtain expressions for the growth rate, adoption wage rate and adoption profits. In all expressions, $H_{a}=\eta_{g} E_{h}$, is stochastic.

\begin{tabular}{|l|l|}
\hline$E_{h}<\widehat{E}_{h}$ (interior growth) & $E_{h} \geq \widehat{E}_{h}$ (maximal growth) \\
\hline$x=1+\left(H_{a}\right)^{\theta}$ & $x=\lambda$ \\
$w_{a}=\theta x\left(H_{a}\right)^{\theta-1}=\theta\left(H_{a}\right)^{\theta-1}+\theta\left(H_{a}\right)^{2 \theta-1}$ & $w_{a}=\theta \lambda\left(H_{a}\right)^{\theta-1}$ \\
$\pi_{i}\left(E_{h}, \eta_{g}\right)=(1-\theta)\left(H_{a}\right)^{\theta}+\left(\frac{1}{2}-\theta\right)\left(H_{a}\right)^{2 \theta}$ & $\pi_{m}\left(E_{h}, \eta_{g}\right)=(1-\theta) \lambda\left(H_{a}\right)^{\theta}-\frac{1}{2}(\lambda-1)^{2}$. \\
\hline
\end{tabular}

In Bellman equation (13), profits $\pi$ are an increasing function of $E_{h}$; the "dismiss" option is decreasing in $E_{h}$. We therefore anticipate a threshold $\bar{E}_{h} \in[1, h]$ such that for all $E_{h}<\bar{E}_{h}$ the firm fires and searches for a better workforce-technology match and for all $E_{h} \geq \bar{E}_{h}$ it proceeds with production using the current workforce. Two cases arise. In the first, $\bar{E}_{h}<\widehat{E}_{h}$, and for some or all of the $E_{h}$ draws for which the adoption option is chosen, maximal growth will not result; therefore, the expected aggregate growth rate $E(x)<\lambda$. In the second, $\bar{E}_{h} \geq \widehat{E}_{h}$, and for every draw of $E_{h}$ for which the adoption option is chosen, maximal growth will result; therefore, $E(x)=\lambda$.

Solving the Bellman equation (13) implicitly defines the $\bar{E}_{h}\left(\eta_{g}\right)$ schedule

$$
\begin{gathered}
f \eta_{g}\left\{\left(1-F\left(\bar{E}_{h}\right)\right) \bar{E}_{h}+\int_{1}^{\bar{E}_{h}} E_{h} d F\left(E_{h}\right)\right\} \gtreqless \\
(1-C)\left[\int_{\bar{E}_{h}}^{\widehat{E}_{h}} \pi_{i}\left(E_{h}, \eta_{g}\right) d F\left(E_{h}\right)+\int_{\widehat{E}_{h}}^{h} \pi_{m}\left(E_{h}, \eta_{g}\right) d F\left(E_{h}\right)-\left(1-F\left(\bar{E}_{h}\right)\right) \pi_{i}\left(\bar{E}_{h}, \eta_{g}\right)\right],
\end{gathered}
$$

which holds with equality if $\bar{E}_{h} \in(0,1)$. The left hand side is the marginal cost of firing the workforce and waiting for a better draw and the right hand side is the marginal benefit of such a draw in the form of extra expected net profits. ${ }^{22}$

It can be shown that the $\bar{E}_{h}\left(\eta_{g}\right)$ curve is decreasing. As $\eta_{g}$ increases, the firing cost increases linearly since it is paid for every person hired. Profits increase, but less than linearly, given diminishing returns to $H_{a}$. Therefore the firm "experiments" less in adoption. Additionally, profits are high on account of high $\eta_{g}$, and therefore the firm does not have to set a high productivity threshold in order to realize high profits and meet adoption costs.

${ }^{21}$ These cutoffs are defined by:

$$
\eta_{g}^{1} \equiv \frac{(\lambda-1)^{\frac{1}{\theta}}}{h}<(\lambda-1)^{\frac{1}{\theta}} \equiv \eta_{g}^{3}
$$

\footnotetext{
${ }^{22}$ When maximal growth results, the firm condition includes only the $\pi_{m}$ term, integrated from $\bar{E}_{h}$ to $h$.
} 
The dependence of the firm condition on $\eta_{g}$ and the various parameters is given by

$$
\begin{gathered}
\bar{E}_{h} \equiv \bar{E}_{h}\left(\eta_{g} ; f, C, \lambda\right) . \\
-;-,-,+
\end{gathered}
$$

For a given $\eta_{g}$, an increase in the unit firing cost of labor, $f$, increases the marginal cost of drawing another $E_{h}$, and the adopting firm experiments less and accepts lower productivity matches for any given $\eta_{g}$; that is, $\bar{E}_{h}\left(\eta_{g}\right)$ decreases. An increase in the regulation cost, $C$, decreases the benefit of redrawing instead of increasing the marginal cost, but produces a similar outcome.

There are two effects of an increase in the growth rate of the available technology, $\lambda$. Since the fixed cost of adopting at the maximum rate, $\frac{1}{2}(\lambda-1)^{2}$, increases, the wage in the adoption sector has to be low enough to keep profits high. Therefore, the minimum adoption labor supply, $\eta_{g}$, needed to induce the firm to adopt at the maximum possible rate increases, and the $\widehat{E}_{h}\left(\eta_{g}\right)$ threshold curve shifts rightward. Second, the expected profit from a higher draw increases, which makes firms more picky and thus increases the adoption threshold $\bar{E}_{h}\left(\eta_{g}\right)$.

\subsection{The Household Condition}

Assuming a parametric form for the cost function, $e(a)=\frac{1}{a}$, noting that $a^{*}=1-\eta_{g}$, and recalling the definition of our education policy variable, $s=\frac{s_{g}}{s_{v}}$, we can write the condition that pins down the threshold ability for general education as

$$
\frac{1}{\left(1-F\left(\bar{E}_{h}\right)\right)} \int_{\bar{E}_{h}}^{h} \log \left(w_{a} E_{h}\right) d F\left(E_{h}\right)-\log \left(w_{n} h\right)=\log \left(\frac{1}{1-\eta_{g}}\right)-\log (s) .
$$

Substituting wages, given in the previous subsection in (18), the household condition $\bar{E}_{h}^{H H}\left(\eta_{g}\right)$ is implicitly defined by

$$
\begin{aligned}
& \frac{1}{\left(1-F\left(\bar{E}_{h}\right)\right)}\left\{\int_{\bar{E}_{h}}^{\widehat{E}_{h}} \log \left[\theta\left(\eta_{g}\right)^{-\theta}\left(E_{h}\right)^{\theta}+\theta\left(E_{h}\right)^{2 \theta}\right] d F\left(E_{h}\right)+\int_{\widehat{E}_{h}}^{h} \log \left[\theta \lambda\left(\eta_{g}\right)^{-\theta}\left(E_{h}\right)^{\theta}\right] d F\left(E_{h}\right)\right\} \\
\gtreqless & \log \left[\theta \beta h^{\theta}\right]+(1-2 \theta) \log \left(\eta_{g}\right)-(2-\theta) \log \left(1-\eta_{g}\right)-\log (s),
\end{aligned}
$$

which holds with equality if $\bar{E}_{h} \in(0,1)$. The left hand side of this expression can be viewed as the benefit of general education in the form of higher expected wages, and the right hand side as the cost, net of subsidy, which includes the foregone wages in the non-adoption sector in addition to the disutility of general education. ${ }^{23}$

It can be shown that the $\bar{E}_{h}^{H H}\left(\eta_{g}\right)$ curve is increasing. As $\eta_{g}$ increases, a downward pressure on adoption wages arises, and the disutility of the marginal general education enrollee

\footnotetext{
${ }^{23}$ In the case of the maximal growth, only the second term within curly braces of the left hand side is present, with the limits of integration being $\bar{E}_{h}$ and $h$.
} 
increases. To counter these, the productivity levels $E_{h}>\bar{E}_{h}$ with which the firm produces and pays wages have to be sufficiently high.

The dependence of the firm condition on $\eta_{g}$ and the various parameters is given by

$$
\begin{array}{r}
\bar{E}_{h}^{H H} \equiv \bar{E}_{h}^{H H}\left(\eta_{g} ; s \lambda\right) . \\
+;-,-
\end{array}
$$

As the subsidy for general education increases, households are willing to supply a given $\eta_{g}$ for lower thresholds $\bar{E}_{h}$ and thus lower wage premia. Expected adoption wages are increasing in $\lambda$; therefore, such an increase induces supply of a given $\eta_{g}$ even for lower thresholds $\bar{E}_{h} \cdot{ }^{24}$

\subsection{Dependence of BGP Equilibrium on Parameters}

Given the decreasing, continuous firm condition $\bar{E}_{h}\left(\eta_{g}\right)$ and the increasing, continuous household condition $\bar{E}_{h}^{H H}\left(\eta_{g}\right)$ we obtain a unique BGP. The intersection of the two schedules yields the equilibrium education allocation $\left(\eta_{g}\right)^{*}$, and productivity threshold $\left(\bar{E}_{h}\right)^{*}$. All other variables, such as the expected growth rate and expected wages on the BGP can then be determined. For instance, the average growth rate in the economy is given by

$$
E(x)=\frac{1}{\left(1-F\left(\left(\bar{E}_{h}\right)^{*}\right)\right)}\left\{\int_{\left(\bar{E}_{h}\right)^{*}}^{\left(\widehat{E}_{h}\right)^{*}}\left[1+\left[\left(\eta_{g}\right)^{*}\left(E_{h}\right)^{*}\right]^{\theta}\right] d F\left(E_{h}\right)+\lambda\left(1-F\left(\left(\widehat{E}_{h}\right)^{*}\right)\right)\right\} .
$$

The expected growth rate $E(x)$ is increasing in the equilibrium values of both $\eta_{g}$ and $\bar{E}_{h}{ }^{25}$

The dependence of the firm and household conditions on the parameters summarized above allows us to characterize their qualitative impact on the BGP equilibrium. An increase in the firing cost parameter $f$ shifts the firm condition downward. As a result, the equilibrium threshold as well as the general education attainment and the expected growth rate decreases. Figure 1 depicts this situation, as well as the components that go into determining the BGP equilibrium. An increase of the entry cost parameter $C$ works similarly.

An increase in the subsidy parameter, $s$, shifts the household's condition down, reducing the equilibrium productivity threshold, but increasing general education attainment. If the latter effect dominates, expected growth increases. As the effective cost of general education decreases with higher $s$, households require a lower threshold productivity and wage premium to choose general education. ${ }^{26}$

\footnotetext{
${ }^{24}$ As in the analysis of the firm condition, the $\widehat{E}_{h}\left(\eta_{g}\right)$ threshold curve shifts to the right when $\lambda$ increases, and the thresholds $\eta_{g}^{1}$ and $\eta_{g}^{3}$ increase.

${ }^{25}$ If $\left(\bar{E}_{h}\right)^{*} \geq\left(\hat{E}_{h}\right)^{*}$, this equation reduces to $E(x)=\lambda$.

${ }^{26}$ Increased subsidies $s$ increase reduces $\bar{E}_{h}$, and therefore the average number of draws before successful production, 1/ $\left(1-F\left(\bar{E}_{h}\right)\right)$. We have abstracted from discounting in our setup for sake of simplicity; the advantage of the subsidy scheme is even more apparent if discounting is taken into account.
} 


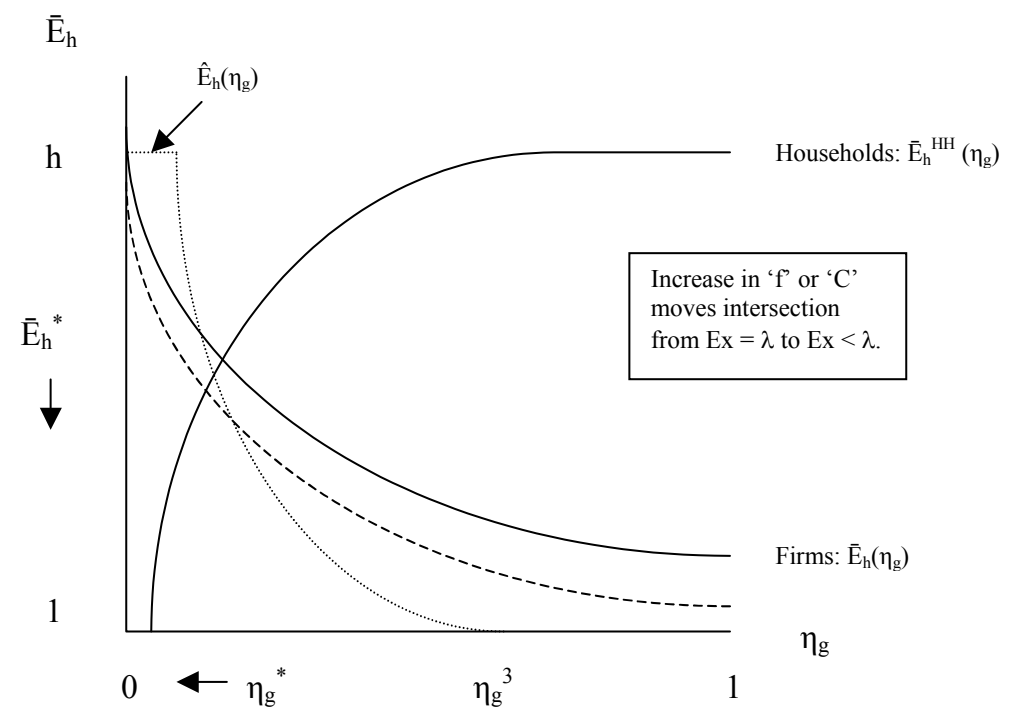

Figure 1: Effect of an increase in $f, C$

Analyzing the dependence of the BGP equilibrium on the speed of technology availability, $\lambda$, is more complicated because all three schedules $-\widehat{E}_{h}\left(\eta_{g}\right)$ (shifts right), $\bar{E}_{h}\left(\eta_{g}\right)$ (shifts up), and $\bar{E}_{h}^{H H}\left(\eta_{g}\right)$ (shifts right) are affected. The impact on the equilibrium productivity threshold $\bar{E}_{h}$ is ambiguous, whereas the equilibrium general education attainment increases unambiguously; the increase in the maximal growth rate increases the expected wage in the adoption sector and therefore the incentive to acquire general education.

What happens to the US-Europe growth gap when $\lambda$ increases? In Figure 2, we hold the household curves at their old positions to achieve graphical tractability; the US household curve lies below Europe's, as a higher subsidy parameter, $s$, is assumed for the US. The accompanying box explains how the growth gap, initially zero, can expand with an increase in $\lambda$. The behavior of the maximal growth cutoff function, $\widehat{E}_{h}\left(\eta_{g}\right)$, is important for this possibility. While the shifts of the firm and household conditions increase the equilibrium general education attainment for Europe, the productivity threshold corresponding to this increased attainment may still fall short of the new $\widehat{E}_{h}$ needed for maximum growth. Alternately, the wages in the adopting sector have to be low enough to induce the firm to adopt at the higher maximum speed. In the US, where general education subsidy and attainment are higher, $\eta_{g}$ can exceed even the increased cutoff $\eta_{g}^{1}$. It may therefore continue to grow at the higher potential rate. 


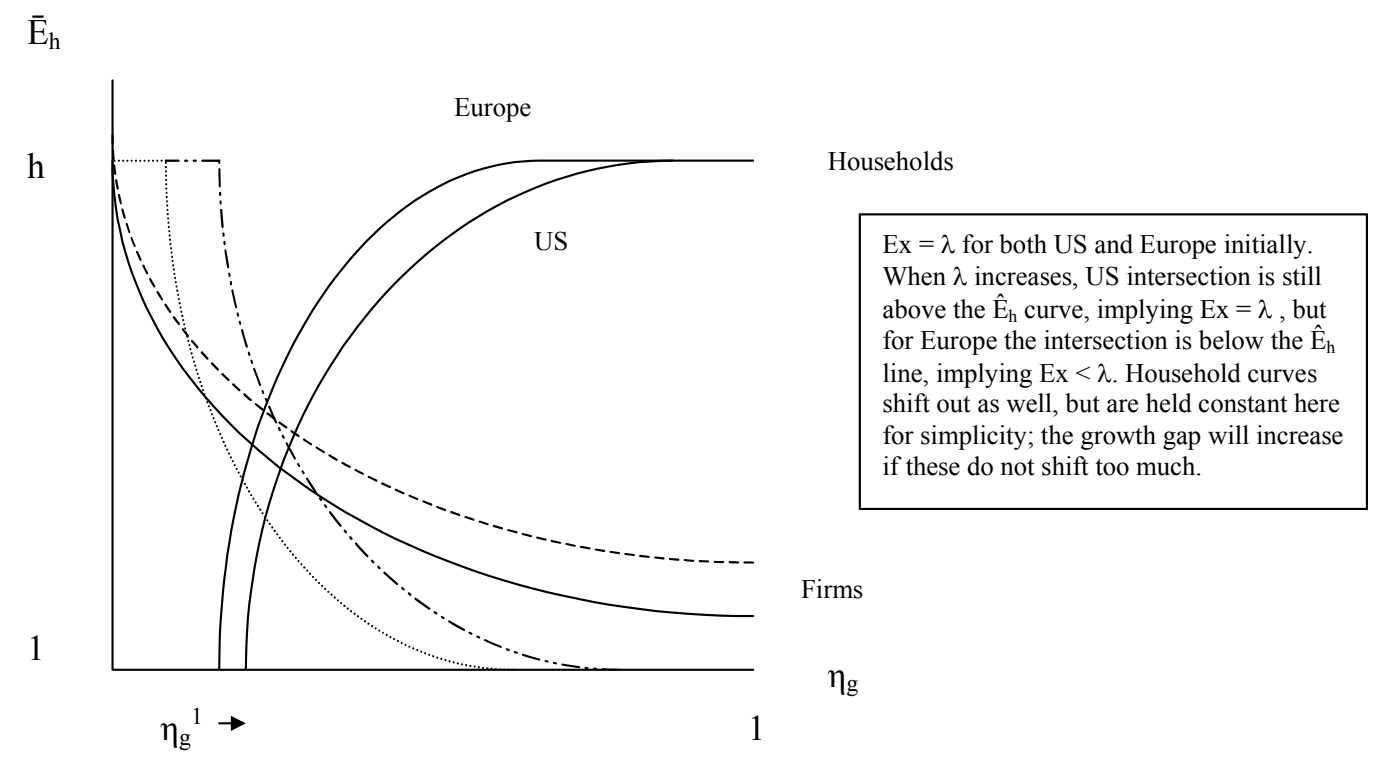

Figure 2: Dependence of the US-Europe growth gap on $\lambda$

Our analytical characterization reveals the qualitative, in some cases ambiguous, impact of the policy variables $(f, C, s)$ on the BGP equilibrium. However, the quantification of the relative importance of each policy's contribution to the US-Europe growth gap requires experimenting with counterfactual experiments using a calibrated version of the model. We turn to this next.

\section{Calibration}

We choose a model period to represent roughly $T=20$ years. We have assumed that a newly adopted technology becomes "common practice" within one model period. Atkeson and Kehoe (2001) discuss the diffusion of electricity in US manufacturing establishments, and report that the time required for the technology to diffuse from $5 \%$ to $50 \%$ "occurred over the 20 years from 1899 to 1919." Therefore, a choice of 20 years for a model period seems to be a reasonable start. ${ }^{27}$

Parameters describing the production technology, $(\lambda, \theta, \beta)$, maximum task-specific productivity, $h$, its distribution $F$, and government policy $(C, f, s)$ need to be chosen. We first

\footnotetext{
${ }^{27}$ The technology of the integrated circuit was invented in 1959 and found large scale use in the personal computer in 1981, a bit more than 20 years later. And the full potential of the personal computer, in turn, was unleashed with the pervasive use of the internet nearly another 20 years later. These observations lend further credibility to our choice of the length of a model period.

Note that our choice of period length has bearing on the interpretation of the magnitudes of some of the parameters in the model, in particular the gross growth rate of the frontier technology $\lambda$ and the firing cost $f$.
} 
pick a subset of "predetermined" parameters motivated by independent empirical evidence. The remaining parameters are then chosen so that our model broadly matches selected empirical growth and education allocation statistics.

\subsection{Predetermined Parameters}

The share parameter $\theta$ in the production function is set to 0.35 . Recall that the production function is of the form $A H^{\theta}$. Since $H$ represents effective units of labor, one can view $\theta$ as the intensity on raw labor as well as on human capital. For instance, the production function in the adopting sector is: $x\left(\eta_{g}\right)^{\theta}\left(E_{h}\right)^{\theta}$; with our choice of $\theta=0.35$, the labor share in this sector equals the commonly assumed value of 0.7. Klenow and Rodriguez (1997) explicitly write the production function as $Y=K^{\alpha} H^{\gamma}(A L)^{1-\alpha-\gamma}$, and use values of $\gamma=0.28$ and $\alpha=0.3$, which implies that $1-\alpha-\gamma=0.42$. In choosing $\theta=0.35$, we slightly overstate the human capital intensity and understate the labor intensity, compared to their study.

In order to calibrate the relative education subsidies $s$ for both the US and Europe we directly use expenditure per student data in PPP dollars. We use upper secondary expenditure as a proxy for $s_{v}$, and university tertiary expenditure as a proxy for $s_{g}$. The values for these from OECD (2001, Table B1.1) imply $s^{U S}=\frac{19802}{7764}=2.55, s^{G E R}=\frac{10139}{9519}=1.07$, $s^{I T}=\frac{6295}{6340}=0.99$. We synthesize this information by choosing $s^{U S}=2.55$ and $s^{E U R}=1$ as our education policy parameters. ${ }^{28}$

Finally, we choose the distribution over productivity draws, $F$, to be uniform over its support $[1, h]$, thus avoiding the introduction of further free parameters. The predetermined parameters are summarized in Table 2.

Table 2

Predetermined Parameters

\begin{tabular}{|l|l|l|l|l|}
\hline Parameter & $\theta$ & $s^{U S}$ & $s^{E U R}$ & $F\left(E_{h}\right)$ \\
\hline Value & 0.35 & 2.55 & 1 & $\frac{E_{h}-1}{h-1}$ \\
\hline
\end{tabular}

\subsection{Parameters Chosen to Match Observations}

As discussed in Section 2, US manufacturing labor productivity grew roughly at $2.5 \%$ a year in the $70 \mathrm{~s}-80 \mathrm{~s}$ and $4 \%$ in the $90 \mathrm{~s}$ and beyond. Recall our assumption that the US grows at the potential rate in both periods; therefore, we choose $\lambda=(1.025)^{20}$ for the rate of

\footnotetext{
${ }^{28}$ Germany and Italy also have data on per pupil expenditure in Tertiary type B programs that "tend to focus on occupationally-specific skills intended for direct labor market entry." (p. 129) and on post-secondary non-tertiary programs, such as "vocational certificates in ... the United States," or "vocational training in the dual system for holders of general upper secondary qualifications in Germany." For Germany, these figures are $\$ 5,422$ and $\$ 10,924$, and for Italy, $\$ 6283$ and $\$ 6,458$ respectively. For the US, there is no data for these categories. For Germany, there is a big disparity between these two figures and the use of the upper secondary figure appears to be a reasonable via media. For Italy, it does not matter much which figure is used.
} 
technological change that prevailed until 1980, and the increased rate $\lambda^{\prime}=(1.04)^{20}$ for the period beyond. As mentioned in the introduction, the European productivity growth rates - roughly the same as the US in earlier period, but, as seen in Table 1, distinctly lower at around $3 \%$ a year during the latter period - are empirical targets.

How do the above choices for $\lambda$ compare with the independent evidence available on the change in the growth rate of available technologies? Cummings and Violante (2002) compute an aggregate index of investment-specific (embodied) technical change, and report that it grew at a rate of $3 \%$ a year until 1975 and reached an average annual rate in excess of $6 \%$ in the 90s. If we assume that this change, besides augmenting the quality of (unmodeled) capital, also augments labor as in the Klenow and Rodriguez (1997) production function, our variable $A$ in the model would have to grow at rates close to $2 \%$ and $4 \%$ in the two periods. $^{29}$

In order to calibrate the remaining parameters $\beta, h, f, C$, both for the US and Europe, we attempt to make our model match the following empirical statistics (with $\lambda^{\prime}$ as rate of technological change, and all other parameters set to their values described above):

- Observations on entry costs are mainly used to pin down $C$, the share of profits not accruing to the entrepreneur. ${ }^{30}$ Using data on official cost of entry procedures from the "Entry Regulations" part of the "Doing Business" database of the World Bank we find, that, as a percentage of gross national income, that cost is $0.6 \%$ for the US, $5.8 \%$ for Germany, and $22.7 \%$ for Italy. For the US we use, as a benchmark target, a ratio of $e n t^{U S}=0=C^{U S}$, and for Europe we use the German value of ent $t^{E U R}=0.058$, since the extremely high value for Italy is an outlier within the EU. ${ }^{31}$ Indeed, the more comprehensive index for barriers to entrepreneurship constructed by Nicoletti, Scarpetta, and Boylaud (1999) - US: 1.3, Germany: 2.1, Italy: 2.7, with 0 being least regulated and 6 most - suggests that Italy fares only slightly worse than Germany in

\footnotetext{
${ }^{29}$ With a residual capital intensity of 0.3 , and the assumed raw labor intensity of 0.35 , the growth rate of $A$ in our model should be 0.65 times the growth rate of the reported technical change. Our assumption that the technical change is capital- and raw-labor-augmenting lies in between the assumptions that it is only capital augmenting and it is neutral. In another highly relevant study, Greenwood and Yorukoglu (1997) suggest rates of technical change of $3 \%$ until the 70 s and $5 \%$ beyond.

${ }^{30}$ It is understood that all parameters discussed below affect all equilibrium quantities, albeit to different degrees. We associate a parameter with the statistic whose equilibrium behavior it most affects.

The use of an alternate calibration strategy that associates $C$ with the tax rate on corporate profits, $35 \%$ for the US and $50 \%$ for Europe, does not alter our conclusions significantly. While net profits consumed by entrepreneurs is obviously sensitive to $C$, the equilibrium allocations and growth rate are not.

${ }^{31}$ As we will document below, this parameter does not have a large effect on equilibrium allocations.

The entry cost database is described in Djankov, La Porta, Silanes, and Shleifer (2001) and can be found in http://rru.worldbank.org/DoingBusiness/TopicReports/EntryRegulations.aspx.
} 
this regard. The corresponding model statistic is

$$
\text { ent }=\frac{\frac{C}{1-F\left(E_{h}\right)} \int_{\bar{E}_{h}}^{h} \pi\left(E_{h}, \eta_{g}\right) d F\left(E_{h}\right)}{\beta\left[\left(1-\eta_{g}\right) h\right]^{\theta}+\frac{\int_{\bar{E}_{h}}^{h} x\left(E_{h}, \eta_{g}\right)\left(\eta_{g} E_{h}\right)^{\theta} d F\left(E_{h}\right)}{1-F\left(\bar{E}_{h}\right)}},
$$

where the numerator is the expected (or aggregate) total cost paid by adoption firms and the denominator is the GDP of the economy.

- Firing costs are used to mainly pin down $f$. We set $f=0$ for the US; for Europe we set $f$ in such a way that firing a worker once costs 6 weeks of her average wage in the model, as suggested by Nagypál (2001). ${ }^{32}$ Given that our model period is 20 years, we choose $f^{E U R}$ so that

$$
f^{E U R}=\frac{6}{20 * 52} * \frac{\int_{\bar{E}_{h}}^{h} w_{a}\left(E_{h}, \eta_{g}\right) E_{h} d F\left(E_{h}\right)}{1-F\left(\bar{E}_{h}\right)} .
$$

- The fraction of population with general education, $\eta_{g}$, for the US will be used to mainly pin down $h$. Education attainment data from OECD 2001 (tables A2.1.a and C2.1) is used to calculate $\eta_{g} \cdot{ }^{33}$ We realistically assume that workers with lower secondary education or less are not able to work in the high-tech sector. In dividing the upper secondary education attainment into "vocational" and "general", we have assumed that enrollment mirrors attainment: vocational enrollments of $6.8 \%$ for the US, and $64.6 \%$ for Germany and Italy. ${ }^{34}$ As described in footnote 28 , we associate postsecondary non-tertiary education and tertiary B education with vocational education. University tertiary education counts toward general education. Based on these figures we compute the fractions of agents with general education as, $\eta_{g}^{U S}=0.745, \eta_{g}^{G E R}=$

\footnotetext{
${ }^{32}$ As discussed in Section 3.3, $f$ cannot be set exactly to zero as the firms' Bellman equation may not have a solution. We set it to a very small number for the US, corresponding to less than one day of average wages. Our results are not sensitive to this choice.

Pries and Rogerson (2001) consider a range of values for the real resource costs involved in dismissing a worker, the maximum of which is $10 \%$ of quarterly wages in the model (i.e. $2.5 \%$ of yearly wages). Lazear (1990) presents data on the number of months of salary given to workers upon dismissal after 10 years of service. It is zero for the US, 1 month for Germany, and 15.86 months for Italy! Nicoletti et.al. provide indices for employment protection legislation: 0.2 for the US, 2.8 for Germany, and 3.3. for Italy on a 0 to 6 scale. The World Bank entry costs database mentioned earlier also give an index measure - 0.94 for the US, 1.75 for Germany, and 1.35 for Italy. While there is variation in the exact magnitude of costs reported, the relative ranking of firing costs is preserved across the US and "Europe".

${ }^{33}$ For the US, $5 \%$ of the population has only primary education, $8 \%$ lower secondary, $51 \%$ upper secondary, $0 \%$ post-secondary non-tertiary, $8 \%$ tertiary B, and $27 \%$ university tertiary. These figures are $2 \%, 17 \%, 53 \%$, $5 \%, 10 \%$, and $13 \%$ for Germany, and $25 \%, 32 \%, 30 \%, 4 \%, 0 \%$, and $9 \%$ for Italy.

${ }^{34}$ The $6.8 \%$ figure for the US is the percentage of students who completed $30 \%$ or more of all credits in specific labor market preparation courses in 1990. See Medrich, Kagehiro, and Houser (1994).
} 
0.317 and $\eta_{g}^{I T}=0.196$. As calibration targets we therefore choose $\eta_{g}^{U S}=0.745 \mathrm{In}$ contrast to policy parameters, where there exist obvious differences across the US and Europe, it is less obvious that the parameter $h$ ought to vary across regions. We thus choose $h$ to roughly match the US education attainment and use the same $h$ for Europe. The (in)-ability of the model to match the European education attainment is then an important quantitative test of the model. In other words, the US education attainment is used in the calibration, while the European attainment of $\eta_{g}^{E U R} \approx 0.2-0.3$ is an empirical target.

- The wage premium is used to mainly determine $\beta$, the constant in the production function of the nonadopting sector. At the heart of our model is the endogenous education decision by households, which is driven by relative wages in the two sectors. It is therefore important to calibrate our model to be consistent with empirically measured premia for general education in both regions. The OECD (1997, Table E4.1a) provides the relative earnings of persons aged 25-64 (normalizing income of workers with upper secondary education to 100). These figures are given for tertiary and nonuniversity tertiary (vocational) categories. For the US the numbers are 174 and 119, for Germany 163 and 111. For the US we thus obtain a general education wage premium $w p^{U S}=\frac{174}{119}=1.46$. For Germany this ratio is $w p^{G E R}=1.47$, slightly higher. ${ }^{35}$ We use the German value as our target for Europe. In particular, note that this premium differs from the "college premium". In the model, the corresponding statistic is computed by dividing expected wages in the adopting sector by nonadopting wages,

$$
w p=\frac{\frac{1}{\left(1-F\left(E_{h}\right)\right)}\left[\int_{\bar{E}_{h}}^{h} w_{a}\left(E_{h}, \eta_{g}\right) E_{h} d F\left(E_{h}\right)\right]}{w_{n}\left(\eta_{g}\right) h} .
$$

\section{Table 3}

\section{Calibrated Parameters}

\begin{tabular}{|l|l|l|l|l|l|l|l|l|l|}
\hline Parameter & $\lambda$ & $\lambda^{\prime}$ & $h$ & $C^{U S}$ & $C^{E U R}$ & $f^{U S}$ & $f^{E U R}$ & $\beta^{U S}$ & $\beta^{E U R}$ \\
\hline Value & 1.64 & 2.19 & 2.4 & 0.0 & 0.34 & 0.0 & 0.011 & 0.76 & 2.05 \\
\hline
\end{tabular}

Our procedure for selecting parameters yields results summarized in Table 3. Obtaining this table involves computing the balanced growth equilibrium with candidate parameter values by using the firm and household conditions, (17) and (19), discussed in Section 4, until the calibration targets are matched to a satisfactory degree. In the next section we report how well the model outcomes and target statistics match, before turning to counterfactual policy experiments. ${ }^{36}$

\footnotetext{
${ }^{35}$ The non-university tertiary wage is unavailable for Italy.

${ }^{36}$ Note that the value for the non-adoption production function parameter, $\beta$, which is chosen to match the
} 


\section{Quantitative Results}

We present our quantitative analysis in two steps. First, we assess whether the model can qualitatively and, more importantly, quantitatively match the key empirical targets set out in the previous section, both for the US and Europe at different points of time. Since it turns out that the model outcomes broadly match the data, we next use it to "decompose" the recent US-Europe productivity growth differentials by differences in the proxies for policies - the product market friction, $C$, labor market friction, $f$, and focus on general education, $s$.

\subsection{Quantitative Evaluation of Model}

In Table 4 we summarize the quantitative predictions of our model. ${ }^{37}$ All variables with primes refer to the 1990s. Recall that we chose a total of 9 parameters to match 9 calibration targets. ${ }^{38}$ The model attains its calibration targets almost exactly (which is not automatic, since model statistics are nonlinear functions of model parameters and a system of 9 equations in 9 variables does not always have a solution).

There were a total of 12 empirical statistics we reported in the previous section, so that we have three "overidentifying restrictions" - European growth rates in both periods and its education allocation were not part of the calibration. The model does very well in almost exactly matching these empirical targets as well; these targets and the corresponding model outcomes are highlighted in bold in Table 4. These findings give us some confidence that our model indeed allows us to decompose, in the next subsection, the recent growth differentials between the US and Europe in a quantitatively meaningful way.

Table 4

Targets and Model Predictions

\begin{tabular}{|l|l|l|l|l|}
\hline Variable & US, Target & US, Model & Europe, Target & Europe, Model \\
\hline$E(x)$ & $2.5 \%$ & $2.5 \%$ & $\mathbf{2 . 9} \%$ & $\mathbf{2 . 5} \%$ \\
\hline$E(x)^{\prime}$ & $4 \%$ & $4 \%$ & $\mathbf{3} \%$ & $\mathbf{3 . 2} \%$ \\
\hline$\eta_{g}^{\prime}$ & $74.5 \%$ & $74 \%$ & $\mathbf{3 0} \%$ & $\mathbf{3 1} \%$ \\
\hline$w p^{\prime}$ & 1.46 & 1.46 & 1.47 & 1.47 \\
\hline$f i r^{\prime}$ & 0 & 0 & 6 weeks & 6 weeks \\
\hline$e n t^{\prime}$ & 0 & 0 & $0.058 \%$ & $0.058 \%$ \\
\hline
\end{tabular}

wage premium of an economy, is higher for Europe than the US. This calibration outcome is reminiscent of the much-documented "wage compression" in Europe. See, for instance, Acemoglu (2002) and the references therein.

\footnotetext{
${ }^{37}$ The growth rates are presented on an annual basis.

${ }^{38}$ Strictly speaking, we only set out to match 7 statistics, since our choices of $\lambda, \lambda^{\prime}$ only enable, but do not ensure that the model matches selected productivity growth observations.
} 
The model also predicts how education allocations and wage premia, both in Europe as well as in the US, change in response to the increased speed at which technologies arrive. As demonstrated in the theoretical part of our paper and confirmed in Table 5, the model predicts an increase in the share of the population with general education. The non-prime variables, again highlighted in bold, were not part of the calibration. Evidently, the increase for Europe is not strong enough to cause the corresponding productivity threshold to exceed the cutoff needed for maximal growth. ${ }^{39}$

What is not obvious from the theoretical analysis is the response of the wage premium to a change in $\lambda$; on one hand the supply of generally skilled workers increases, on the other hand faster technology adoption fuels higher demand for those workers. The theoretical effect on the wage premium is ambiguous, but, as Table 5 shows, the demand effect dominates in both cases and leads to an increase in the wage premium in both regions; the effect is stronger for the US. Even though the wage premium of our model refers to workers with general, relative to those with vocational education, rather than to workers with college vs. high school education, it is interesting that the above prediction is broadly consistent with the empirical evidence (for example, see Gottschalk and Smeeding, 1997).

Table 5

Ancillary Model Statistics

\begin{tabular}{|l|l|l|}
\hline Variable & US, Model & Europe, Model \\
\hline$\eta_{g}$ & $\mathbf{6 9} \%$ & $\mathbf{2 9} \%$ \\
\hline$\eta_{g}^{\prime}$ & $74 \%$ & $31 \%$ \\
\hline$w_{p}$ & $\mathbf{1 . 2 6}$ & $\mathbf{1 . 4 0}$ \\
\hline$w_{p}^{\prime}$ & 1.46 & 1.47 \\
\hline
\end{tabular}

\subsection{Decomposition of Recent US-Europe Growth Differentials}

We are now in a position to perform a model-based decomposition of the growth gap that emerged in the 1990s between Europe and the US. We start with the European situation in the 1990s (see column 5 of Table 4 ). We then sequentially reduce the product market friction to zero $(C=0)$, then the labor market friction also to zero $(f=0)$, and finally increase the education subsidy to US levels, thus arriving at the US situation (see column 3 of Table 4). For all experiments we adjust $\beta$ in such a way as to keep the wage premium constant at the empirically observed value. Table 6 summarizes the results of this thought experiment.

\footnotetext{
${ }^{39}$ The European Competitiveness Report 2001 bemoans the lack of adaptability of the labor force to new technologies: “... in recent years skill shortages in important technology areas have been reported in several European countries... It appears that, unlike in previous years, when the long-term trend increase in the demand for skills was met by the supply of technology professionals from the educational system, the surge in demand for ICT-related skills in the 1990s found no corresponding supply forthcoming."
} 
Table 6

Decomposition of Growth Gap

\begin{tabular}{|l|l|l|l|l|}
\hline Variable/Parameter & Europe & Eur., $C=C^{U S}$ & Eur., $C=C^{U S}, f=f^{U S}$ & US \\
\hline$E(x)$ & $3.20 \%$ & $3.23 \%$ & $3.38 \%$ & $4 \%$ \\
\hline$\eta_{g}$ & 0.31 & 0.32 & 0.35 & 0.74 \\
\hline $\bar{E}_{h}$ & 1.98 & 2.05 & 2.36 & 2.39 \\
\hline$\beta$ & 2.05 & 2.03 & 1.96 & 0.76 \\
\hline
\end{tabular}

Our key finding is that the majority of the growth gap stems from differences in educational policy. Columns 2 and 3 of the table demonstrate that a reduction of the share of GDP lost to regulation from $6 \%$ to $0 \%$ only increases the growth rate by three-hundreds of one percent and leaves the education allocation almost unchanged. Only the threshold productivity $\bar{E}_{h}$ increases somewhat, by about $4 \%$.

The growth gap explained by the firing cost is more sizeable, amounting to 0.15 percentage points. Lower firing costs allow firms to wait for more productive draws and yield higher expected wages in the adoption sector, increasing the fraction of the population opting for general education.

The relatively modest growth effects of labor and product market frictions implied by our model therefore leave the bulk of the growth gap, 0.62 percentage points, to be explained by the marked difference in educational focus between the US and Europe. Our quantitative results are not sensitive to the sequential order in which European labor, product market and education policies are changed to their corresponding US values: increasing $s$ from 1 to 2.55 and leaving $f, C$ at their European values again attributes more than 0.6 percentage points of the growth gap (of the 0.8 points predicted by the model) to differences in education policies.

An alternate decomposition, which views the parameter $\beta$ as structural and maintains it at the prevailing value of 2.05 for Europe, is shown in Table 7 . While the gap between Europe and the US cannot quite be bridged (suggesting that policies easing wage compression might warrant further attention), the education policy difference continues to account for most of the growth gap.

\section{Table 7}

Decomposition of Growth Gap - constant $\beta$

\begin{tabular}{|l|l|l|l|l|}
\hline Variable/Parameter & Europe & Eur., $C=C^{U S}$ & Eur., $C=C^{U S}, f=f^{U S}$ & "US" \\
\hline$E(x)$ & $3.20 \%$ & $3.22 \%$ & $3.35 \%$ & $3.81 \%$ \\
\hline$\eta_{g}$ & 0.31 & 0.32 & 0.34 & 0.57 \\
\hline$\beta$ & 2.05 & 2.05 & 2.05 & 2.05 \\
\hline
\end{tabular}

Our results are of course specific to the model we use, but may at least suggest that Europe's (especially Germany's and Italy's) focus on vocational education held these countries 
back in a quantitatively significant way in the ICT-age of the 90 s.

\subsection{Sensitivity Analysis}

In Section 5.2, we counted anyone with a college degree toward $\eta_{g}$. However, it is not obvious that college graduates with little technical or professional background should be included in this category. For instance, Ingram and Neumann (2000) analyze returns to various dimensions of skill to argue that variations in mathematical ability accounted for a significant portion of the recent increase in within-group income inequality of college graduates. This suggests that not all college graduates are likely to be suited for employment in high-tech industries. Therefore, now we net out the humanities, arts, and education graduates from the general education pool. ${ }^{40}$ Proceeding as we did earlier, we obtain $\eta_{g}^{U S}=0.672, \eta_{g}^{G E R}=0.288$ and $\eta_{g}^{I T}=0.178$. We therefore aim for a reduced empirical target for Europe of $\eta_{g}^{E U R} \approx 0.25$. Recalibration yields the analogues of Tables 3 and 6, which are presented as Tables 8 and 9 . While Table 6 provides a slightly better fit of the growth rate targets, we can see that our basic conclusion is unchanged in Table 9; the bulk of the growth gap between the US and Europe remains to be explained by the difference in education policy. ${ }^{41}$

Table 8

Calibrated Parameters - modified $\boldsymbol{\eta}_{g}$

\begin{tabular}{|l|l|l|l|l|l|l|l|l|l|}
\hline Parameter & $\lambda$ & $\lambda^{\prime}$ & $h$ & $C^{U S}$ & $C^{E U R}$ & $f^{U S}$ & $f^{E U R}$ & $\beta^{U S}$ & $\beta^{E U R}$ \\
\hline Value & 1.64 & 2.19 & 2.0 & 0.0 & 0.4 & 0.0 & 0.0108 & 0.9 & 2.34 \\
\hline
\end{tabular}

Table 9

Decomposition of Growth Gap - modified $\eta_{g}$

\begin{tabular}{|l|l|l|l|l|}
\hline Variable/Parameter & Europe & Eur., $C=C^{U S}$ & Eur., $C=C^{U S}, f=f^{U S}$ & US \\
\hline$E(x)$ & $2.89 \%$ & $2.90 \%$ & $3.02 \%$ & $3.83 \%$ \\
\hline$\eta_{g}$ & 0.25 & 0.25 & 0.26 & 0.69 \\
\hline $\bar{E}_{h}$ & 1.68 & 1.75 & 1.99 & 1.99 \\
\hline$\beta$ & 2.34 & 2.37 & 2.29 & 0.9 \\
\hline
\end{tabular}

We have fixed the measure of each type of firm at one in our quantitative exercise. Abstracting from the entry decision of firms considerably improves the tractability of our model. Nevertheless, it is interesting to explore the robustness of our quantitative analysis to entry. We do this by assuming that there is a fixed resource cost $A K_{n}$ and $A K_{a}$ of setting

\footnotetext{
${ }^{40}$ We use graduation data from 1999 and assume that attainment in the population mirrors it (see Table C4.3 in OECD, 2001)).

${ }^{41}$ When $\beta$ is held constant at 2.34 , the analogue of Table 7 is obtained. Here too most of the growth gap is explained by the difference in $s$.
} 
up a non-adopting and an adopting firm, respectively. ${ }^{42}$ Let $\mu_{n}, \mu_{a}$ denote the equilibrium measure of entrepreneurs in each sector. The labor market clearing conditions now imply $\mu_{n} H_{n}=\left(1-\eta_{g}\right) h$ and $\mu_{a} H_{a}=\eta_{g} E_{h}$. The entire analysis of Section 4 goes through, with $\left(1-\eta_{g}\right) / \mu_{n}$ replacing $\left(1-\eta_{g}\right)$, and $\eta_{g} / \mu_{a}$ replacing $\eta_{g}$. The following two free-entry conditions, which equate entry costs to expected profits, are the additional equations needed to solve for the two new BGP variables, $\mu_{n}$ and $\mu_{a}$.

$$
\begin{aligned}
K_{n} & =\pi_{n}\left(\eta_{g}, \mu_{n}\right) \\
K_{a} & =\frac{1}{1-F\left(\bar{E}_{h}\right)}\left[\int_{\bar{E}_{h}}^{\hat{E}_{h}\left(\frac{\eta_{g}}{\mu_{a}}\right)} \pi_{i}\left(\eta_{g}, \mu_{a}, E_{h}\right) d F\left(E_{h}\right)+\int_{\hat{E}_{h}\left(\frac{\eta_{g}}{\mu_{a}}\right)}^{h} \pi_{m}\left(\eta_{g}, \mu_{a}, E_{h}\right) d F\left(E_{h}\right)\right] .
\end{aligned}
$$

To impose discipline in our quantitative exercise, we normalize the measures $\mu_{n}, \mu_{a}$ to one for the 1990s for both US and Europe. This implies that the fixed costs equal the respective equilibrium profits. We then use these $K$ 's to recompute the equilibrium for the earlier time period, and produce the analogues of Table 4 and 5, allowing the measure of firms to vary freely. ${ }^{43}$ This strategy does not amount to calibrating the $K$ 's to observable targets, which are, in any case, difficult to identify in data. Nevertheless, it should allow us to verify that our baseline calibration and decomposition do not result only because the fixed factor of entrepreneurial capital is held constant when $\lambda$ increases to $\lambda^{\prime}$. We obtain $K_{n}$ and $K_{a}$ of 0.42 and 1.03 for the US, and 1.59 and 0.44 for Europe. Except for an $\eta_{g}^{\prime}$ of $73.5 \%$ for the US, instead of $74 \%$, the numbers are virtually unchanged from Table 4 . Table 10 presents the analogue of Table 5 .

Table 10

Ancillary Model Statistics - varying $\mu$

\begin{tabular}{|l|l|l|}
\hline Variable & US, Model & Europe, Model \\
\hline$\mu_{a}$ & 1.07 & 1.09 \\
\hline$\mu_{n}$ & 1.23 & 1.03 \\
\hline$\eta_{g}$ & $67.9 \%$ & $29.4 \%$ \\
\hline$\eta_{g}^{\prime}$ & $73.5 \%$ & $31.0 \%$ \\
\hline$w_{p}$ & 1.21 & 1.42 \\
\hline$w_{p}^{\prime}$ & 1.47 & 1.47 \\
\hline
\end{tabular}

There is little change from the earlier table. Given that $\mu_{a}^{\prime}$ and $\mu_{n}^{\prime}$ equal 1 for both regions, the above table indicates that the main effect of incorporating entry in this fashion is a drop in the measure of non-adopting firms in the US. This depresses demand for vocationally educated labor and increases the wage premium by a higher amount than seen in Table 5.

\footnotetext{
${ }^{42} K_{n}$ and $K_{a}$ are to be viewed as technological variables, unlike the policy variable, $C$, introduced earlier.

${ }^{43}$ Given our normalization, Tables 6 and 7 are unchanged.
} 


\section{Conclusion}

The roles of labor market rigidities and excessive regulation in explaining US-Europe growth differences have been studied extensively. In this paper, we draw attention to another possible cause - the focus on skill-specific education in Europe. Our quantitative analysis with a calibrated version of our model shows that the role of education may be significant. Educational reform, in the form of higher flexibility in educational choices made at the upper secondary level, and a greater focus on general education might be important in reducing the US-Europe growth gap that has emerged since the mid 80s.

As conceded above, our model may be geared towards finding a significant role for education. For instance, the education decision determines occupational choice forever. Relaxing this assumption would likely attribute a greater effect to labor market frictions and other impediments to occupational mobility. Indeed, it might be hard to completely disentangle the educational and labor market aspects in practice. Likewise, a model of entry and entrepreneurship is likely to find a more important role for product market and other regulations. Extending the model along these dimensions is a subject for future research.

\section{References}

[1] Acemoglu, Daron (2002). "Cross-Country Inequality Trends," NBER Working Paper 8832 .

[2] Allen, Robert C. (1998). "The Employability of University Graduates in the Humanities, Social Sciences, and Education: Recent Statistical Evidence," Discussion Paper No.: 9815, Department of Economics, The University of British Columbia.

[3] Atkeson, Andrew, and Patrick J. Kehoe (2001). "The Transition to a New Economy After the Second Industrial Revolution," Federal Reserve Bank of Minneapolis Research Department Staff Report.

[4] Bertocchi, Graziella, and Michael Spagat (1998). "The Evolution of Modern Educational Systems: Technical Vs. General Education, Distributional Conflict and Growth." CEPR Discussion Paper 1925.

[5] Bessen, James (2002). "Technology Adoption Costs and Productivity Growth: The Transition to Information Technology," Review of Economic Dynamics, Vol. 5, No. 2, pp. $443-469$.

[6] CERGE-EI (1997). Czech Republic 1997: The Year of Crises.

[7] Cummings, Jason G., and Giovanni L. Violante (2002). "Investment-Specific Technical Change in the US (1947-2000): Measurement and Macroeconomic Consequences," Review of Economic Dynamics, Vol. 5, No. 2, pp. 243-284. 
[8] Djankov, Simeon, La Porta, Rafael, de Silanes, Florencio Lopez, and Shleifer, Andrei (2002). "The Regulation of Entry", Quarterly Journal of Economics, Vol. 117, 1-37.

[9] European Commission (2001). European Competitiveness Report 2001.

[10] Galor, Oded, and Omer Moav (2000). "Ability-Biased Technological Transition, Wage Inequality, and Economic Growth," Quarterly Journal of Economics, Vol. 115, No. 2, pp. 469-497.

[11] Galor, Oded, and Daniel Tsiddon (1997). "Technological Progress, Mobility, and Economic Growth," The American Economic Review, Vol. 87, No. 3, pp. 363-382.

[12] Greenwood, Jeremy, and Mehmet Yorukoglu (1997). "1974," Carnegie-Rochester Conference Series on Public Policy, Vol. 46, pp. 49-95.

[13] Gottschalk, Peter and Timothy Smeeding. "Cross-National Comparisons of Earnings and Income Inequality," Journal of Economic Literature, Vol. 35, No. 2 (June 1997), pp. 633-687.

[14] Ingram, Beth F., and George R. Neumann (2000). "The Returns to Skill." University of Iowa Working Paper.

[15] Klenow, Peter J., and Rodriguez, Andres (1997). "The Neoclassical Revival in Growth Economics: Has it Gone Too Far?" NBER Macroeconomics Annual, 73-103.

[16] Krueger, Dirk, and Krishna B. Kumar (2003), "Skill-specific rather than General Education: A Reason for US-Europe Growth Differences?," NBER Working Paper 9410.

[17] Lawrence, Robert Z., and Charles L. Schultze. (eds.) (1987). Barriers to European Growth: A Transatlantic View. Washington, D.C.: The Brookings Institution.

[18] Lazear, Edward (1990). "Job Security Provisions and Employment," Quarterly Journal of Economics, Vol. 105, No. 3, pp. 699-726.

[19] Merdich, Elliot A., Susan A. Kagehiro, and James Houser (1994). "Vocational Education in G-7 Countries: Profiles and Data," National Center for Education Statistics, Research and Development Report.

[20] Mitchell, Matthew F. (2002), "Technological Change and the Scale of Production," Review of Economic Dynamics, Vol. 5, No. 2, pp. 477-88

[21] Nagypál, Éva (2002). "The Cost of Employment Protection in the Presence of Matchspecific Learning." IIES, Stockholm University Working Paper.

[22] Nicoletti, G., S. Scarpetta, and O. Boylaud (1999). "Summary Indicators of Product Market Regulation with an Extension to Employment Protection Legislation," OECD Economics Department Working Paper 226. 
[23] OECD (1997). Education at a Glance: OECD Indicators 1997. Paris, France: OECD.

[24] OECD (2001). Education at a Glance: OECD Indicators 2001. Paris, France: OECD.

[25] Pries, Michael, and Richard Rogerson (2001). "Hiring Policies, Labor Market Institutions and Labor Market Flows." University of Maryland Working Paper.

[26] Scarpetta, Stefano, Andrea Bassanini, Dirk Pilat and Paul Schreyer. "Economic Growth in the OECD Area: Recent Trends at the Aggregate and Sectoral level," OECD Working Paper 248, June 2000.

[27] Schreyer, Paul (2000). "The Contribution of Information and Communication Technology to Output Growth: A Study of the G7 Countries," OECD STI Working Paper $2000 / 2$.

[28] Stiroh, Kevin J (2002). "Information Technology and the U.S. Productivity Revival: What Do the Industry Data Say?" American Economic Review, Vol. 92, No. 5, pp. 1559-1576.

[29] Stokey, Nancy L., and Rebelo, Sergio (1995). "Growth Effects of Flat-Rate Taxes," Journal of Political Economy 103, 519-550.

[30] Wasmer, Etienne (2002). "Interpreting Europe and US Labor Market Differences: The Specificity of Human Capital Investments," CEPR Discussion Paper 3780. 